\title{
IL-37b gene transfer enhances the therapeutic efficacy of mesenchumal stromal cells in DSS- induced colitis mice
}

\author{
Wei-qiang WANG ${ }^{1}$, Kui DONG ${ }^{1}$, Lu ZHOU ${ }^{1}$, Guo-hui JIAO ${ }^{1}$, Cong-zhong ZHU ${ }^{2}$, Wen-wen $\mathrm{LI}^{1}$, Gang $\mathrm{YU}^{3}$, Wan-tong WU ${ }^{3}$, Song \\ $\mathrm{CHEN}^{3}$, Zhi-na SUN ${ }^{3}$, Yu-ming WANG ${ }^{1}$, Wen-tian $\mathrm{LIU}^{1}$, Jie ZHANG ${ }^{1}$, Bang-mao WANG ${ }^{1,}$, , Xiao-ming FENG ${ }^{3,}$ * \\ Departments of ${ }^{1}$ Gastroenterology and Hepatology and ${ }^{2}$ Gynecology, General Hospital, Tianjin Medical University, Tianjin 300052 , \\ China; ${ }^{3}$ State Key Laboratory of Experimental Hematology, Institute of Hematology and Hospital of Blood Disease, Chinese Academy of \\ Medical Sciences, Tianjin 300020, China
}

\begin{abstract}
Aim: To investigate whether the transfer of the IL-37b gene, a newly identified inhibitor of both innate and adaptive immunity, could improve the therapeutic efficacy of mesenchumal stromal cells (MSCs) in inflammatory bowel disease (IBD).

Methods: The expression of IL-37 in biopsied specimens of the patients with active ulcerative colitis (UC) was detected using RT-PCR and immunohistochemistry. Mice were treated with 3\% dextran sulfate sodium (DSS) for 8 days to induce colitis. Before DSS treatment, the mice were injected with MSCs, MSC-eGFP or MSC-IL37b. Their body weight was measured each day, and the colons and spleens were harvested on d 10 for pathological and biochemical analyses.

Results: In biopsied specimens of the patients with active UC, the expression of IL-37 was dramatically elevated in inflamed mucosa, mainly in epithelial cells and infiltrating immune cells. Compared to MSC-eGFP or MSCs, MSC-IL37b administration significantly attenuated the body weight and colon length reduction, and decreased the histological score in DSS-induced colitis mice. Furthermore, MSC-IL37b administration increased the percentage of myeloid-derived suppressor cells (MDSCs) among total splenic mononuclear cells as well as the percentage of regulatory T cells (Tregs) among splenic CD4 ${ }^{+}$T cells in the mice. Moreover, MSC-IL37b administration increased the IL-2 ${ }^{+}$cells and decreased the IFN- $\mathrm{Y}^{+}$cells among splenic CD4 ${ }^{+} \mathrm{T}$ cells.

Conclusion: IL-37 is involved in the pathophysiology of UC. IL-37b gene transfer enhances the therapeutic efficacy of MSCs in DSSinduced colitis mice by inducing Tregs and MDSCs and regulating cytokine production.
\end{abstract}

Keywords: inflammatory bowel disease; colitis; dextran sulfate sodium-induced colitis mice; mesenchymal stromal cells; IL-37b; regulatory T cells; myeloid-derived suppressor cells; inflammatory cytokines

Acta Pharmacologica Sinica (2015) 36: 1377-1387; doi: 10.1038/aps.2015.51; published online 20 Jul 2015

\section{Introduction}

Inflammatory bowel disease (IBD), which primarily includes ulcerative colitis (UC) and Crohn's disease (CD), is a group of autoimmune diseases that are characterized by inflammation of both the small and large intestine; in IBD, elements of the digestive system are attacked by the body's own immune system $^{[1]}$. Anti-inflammatory and immunosuppressant drugs are commonly used to treat IBD. In addition, infliximab, a chimeric monoclonal antibody against tumor necrosis factor alpha (TNF-a), has therapeutic benefit in patients who have failed conventional therapy and who are hospitalized with severe

\footnotetext{
* To whom correspondence should be addressed.

E-mail tjmughgi@hotmail.com (Bang-mao WANG); xfeng1979@hotmail.com (Xiao-ming FENG)

Received 2015-02-09 Accepted 2015-05-18
}

IBD $^{[2]}$. Despite the advances in the treatment of IBD, a lack of efficacious therapies remains, and the currently available therapies are associated with side effects such as headache, diarrhea, and nausea, which can reduce patient compliance and thereby exacerbate the condition ${ }^{[1]}$.

MSCs are adult somatic cells that have the potential to differentiate along the osteogenic, chondrogenic, and adipogenic lineages both in vitro and in vivo. In addition, MSCs exert anti-inflammatory activity by suppressing activated $\mathrm{T}$ cell proliferation and cytokine production, skewing macrophages toward the immunosuppressive M2 phenotype, preventing respiratory bursts from neutrophils, and inhibiting the activation of dendritic cells (DCs), natural killer cells (NKs) and mast cells $^{[3]}$. Therefore, much research has examined the therapeutic efficacy of MSCs on inflammation-induced tissue injury, including IBD. However, the success of MSC-based therapy is 
limited in IBD. For example, the therapeutic efficacy of MSCs in animal models of colitis had to be further improved via multiple injections, anti-addressin antibody coating or IFN- $\gamma$ pretreatment ${ }^{[4-6]}$. In clinical trials, the results of MSC therapy for fistulizing CD and luminal CD have been inconsistent, and further research is necessary to improve the efficacy of MSC therapy ${ }^{[7]}$. Genetic modification of MSCs using viral vectors is one option to improve their therapeutic potential.

IL-37 (formerly named IL-1F7) is the most recently identified member of the IL-1 family. Currently, IL-37 has been identified only in certain types of human cells, and a mouse homolog has not been identified. IL-37b is the best characterized isoform of the various splice variants of IL-37 ${ }^{[8]}$. IL-37b exhibits potent immunosuppressive functions against both innate and adaptive immunity. The expression of IL-37b in macrophages or epithelial cells almost completely suppresses the production of proinflammatory cytokines ${ }^{[9,10]}$. Mice that transgenically express human IL-37b are protected from lipopolysaccharide (LPS)-induced septic shock and dextran sulfate sodium-induced colitis through the inhibition of DCs activation and the downregulation of circulating and tissue cytokines $^{[10,11]}$. In addition, the transgenic expression of IL-37b suppresses skin contact hypersensitivity to dinitrofluorobenzene by impairing the activation of effector $\mathrm{T}$ cell responses and inducing Tregs ${ }^{[12]}$. Recombinant IL-37b represses proinflammatory cytokine and chemokine production, neutrophil infiltration and cellular apoptosis, thus protecting mice against hepatic and myocardial ischemia/reperfusion injury ${ }^{[13,14]}$. The administration of IL-37b plasmid DNA reduces local and systemic inflammation in a mouse model of Con A-induced hepatitis and psoriasis by downregulating proinflammatory cytokines $^{[15,16]}$.

Given the potent immunosuppressive functions of IL-37b, we aimed to determine whether IL-37b gene transfer could augment the therapeutic efficacy of MSCs in DSS-induced colitis, which is one of the most widely used chemically induced models of IBD. This study demonstrates that the intraperitoneal administration of MSC-IL-37b reduced the incidence of clinically severe DSS-induced colitis to a greater extent than MSCs alone. The frequencies of both Tregs and MDSCs among splenic mononuclear cells were significantly upregulated in mice treated with MSC-IL-37b. Moreover, in splenic $\mathrm{CD}^{+} \mathrm{T}$ cells in the MSC-IL-37b group, the expression of the pro-inflammatory cytokine IFN- $\gamma$ was reduced, and the expression of the anti-inflammatory cytokine IL-2 was increased. These results indicate that IL-37b gene transfer may be an alternative method for improving the therapeutic efficacy of MSCs in colitis and confirm the protective role of IL-37b in inflammatory disorders.

\section{Materials and methods UC tissue samples}

The ethics committee of the General Hospital of Tianjin Medical University approved this project. The diagnosis of UC was based on conventional clinical and endoscopic criteria. The clinical activity was determined according to the colitis activity index for $\mathrm{UC}^{[17]}$. All the patients were treated with salicylates, but none of the patients received treatment with corticosteroids or azathioprine before the biopsied specimens were obtained.

For the RT-PCR analysis of IL-37 mRNA expression in affected colon tissues, biopsied specimens were obtained from 9 patients with active UC who were undergoing an endoscopic examination; informed consent was obtained from all these patients. Normal colorectal tissues were obtained by surgical resection of colon cancer at distal tumor sites $(n=6)$. All the biopsied specimens were snap-frozen in liquid nitrogen and then transferred to $-80^{\circ} \mathrm{C}$ for storage until processing.

For the histological grading of H\&E-stained sections and IL-37 immunohistochemistry, paraffin embedded tissues from 6 healthy subjects and 30 patients with active UC were obtained from the Department of Pathology of General Hospital of Tianjin Medical University. These patients underwent an endoscopic examination during the period from April 2013 to September 2013 when they were diagnosed with active UC. Paraffin-embedded tissues were cut into 3 - $\mu \mathrm{m}$ sections that were used for H\&E staining or immunohistochemistry.

\section{Histological grading of the UC-affected colon tissues}

The H\&E-stained sections were graded in a blinded fashion by two pathologists according to a scoring system modified from a previous study ${ }^{[18]}$ : grade 0 , no neutrophils in the lamina propria (LP); grade I, a few neutrophils $(<10 / \mathrm{HPF})$ in the LP with minimal infiltration of the crypts; grade II, prominent neutrophils (approximately 10-50/HPF) in the LP with infiltration of $>50 \%$ of the crypts; grade III, massive neutrophil deposition in the LP with crypt abscesses; and grade IV, florid acute inflammation with ulceration.

\section{Immunohistochemistry}

Immunohistochemical analyses were performed on the 3- $\mu \mathrm{m}$ paraffin sections using a previously published procedure with certain modifications ${ }^{[19]}$. Briefly, after antigen retrieval, the sections were incubated at $4^{\circ} \mathrm{C}$ overnight with a rabbit antihuman IL-37 polyclonal antibody (1:300 dilution; Thermo Scientific, Rockford, USA) or with an anti-human IL-18 polyclonal antibody (1:250 dilution; Abcam, Cambridge, UK). Then, biotin-conjugated goat anti-rabbit IgG was applied to the sections for $30 \mathrm{~min}$ at $37^{\circ} \mathrm{C}$. Finally, 3,3'-diaminobenzidine tetrahydrochloride was used to visualize the staining, and hematoxylin was added for counterstaining.

\section{MSC isolation from mouse compact bones and MSC culture}

Mouse MSCs were isolated and cultured as previously described with minor modifications ${ }^{[20]}$. Briefly, 2- to 3-weekold female C57BL/ 6 mice were euthanized, and the humeri, tibiae and femurs were carefully cut into chips of approximately 1-3 $\mathrm{mm}^{3}$ with scissors. The chips were digested with $1 \mathrm{mg} / \mathrm{mL}$ of collagenase II (Invitrogen, Carlsbad, USA) for $2 \mathrm{~h}$ at $37^{\circ} \mathrm{C}$ with shaking at $200 \mathrm{r} / \mathrm{min}$. The enzyme-treated bone chips were then seeded into a $25-\mathrm{cm}^{2}$ plastic culture flask in the presence of $6 \mathrm{~mL}$ of complete media. The cells were used 
at passages 3-5 for experiments, unless otherwise specified.

\section{Flow cytometric analysis}

Unless otherwise specified, the reagents and antibodies used in this study were purchased from eBioscience (San Diego, USA). For the MSC immunophenotypic analysis, cell surface molecules were stained using mouse anti-CD29, anti-CD44, anti-Sca-1, anti-CD45, and anti-CD31 antibodies. For the Treg analysis, the cell preparations were stained with anti-CD4 and anti-CD25 to analyze cell surface marker expression; subsequently, the cells were fixed and permeabilized with fixationpermeabilization buffers and then stained with anti-Foxp3. Tregs were sorted using antibodies against CD4 and CD25. MDSCs were analyzed or sorted using antibodies against CD11b and Gr-1. For intracellular cytokine staining (ICS), cells were stimulated for $6 \mathrm{~h}$ with phorbol 12-myristate 13-acetate (50 ng/mL) and ionomycin $(500 \mathrm{ng} / \mathrm{mL}$ ) in the presence of GolgiPlug (BD Pharmingen, San Diego, CA, USA). Then, cell surface molecules were stained using anti-CD4 and anti-CD8, and the cells were subsequently fixed and permeabilized with a Cytofix/Cytoperm Plus kit and stained with the following antibodies: anti-IL-2, anti-IL-4, anti-IL-17 and anti-IFN-ү. The Tregs, MDSC or ICS analyses were performed on cells derived from the spleens of mice in different groups at the end of the experiment. Tregs and MDSCs were sorted from cell populations derived from the spleens of wild-type C57BL/6 mice. For all of these assays, cells were incubated with antibodies for $40 \mathrm{~min}$ in the dark at $4^{\circ} \mathrm{C}$. Afterwards, the cells were washed once with PBS with 1\% Fetal Calf Serum (FCS), resuspended in $500 \mu \mathrm{L}$ of PBS and immediately analyzed. All the analyses were performed using an LSR II flow cytometer (BD Biosciences, San Diego, CA, USA), and the data were analyzed with FlowJo software (Tree Star, San Carlos, CA, USA).

\section{Adipogenic and osteogenic differentiation of MSCs}

We differentiated MSCs into the adipogenic and osteogenic lineages following the procedure published by ZHU et al ${ }^{[20]}$. Briefly, MSC monolayers were treated with adipogenic medium consisting of a-MEM supplemented with 10\% FCS (Invitrogen, Carlsbad, USA), 0.5 mol/L 3-isobutyl-1-methylxanthine (IBMX), $10^{-6} \mathrm{~mol} / \mathrm{L}$ dexamethasone and $10 \mathrm{ng} / \mathrm{mL}$ insulin (Sigma-Aldrich, St Louis, MO, USA). For osteogenic differentiation, confluent MSC monolayers were treated with osteogenic medium consisting of a-MEM supplemented with 10\% FCS, $10 \mathrm{mmol} / \mathrm{L} \beta$-glycerophosphate, 50 Hmol/L ascorbate-2-phosphate, and $10^{-7} \mathrm{~mol} / \mathrm{L}$ dexamethasone (SigmaAldrich, St Louis, MO, USA). Osteoblastogenesis was assessed by in situ Alizarin Red $S$ and von Kossa staining as described previously after 4 weeks of induction. Successful adipogenic differentiation of MSCs was determined by Oil Red O staining. Photomicrographs were taken with an inverted microscope (Olympus CK2, Tokyo, Japan) and a digital camera (Nikon Coolpix 4500, Tokyo, Japan).

\section{IL-37b gene transfer into MSCs}

We previously constructed Ad-IL-37b (an adenovirus vector expressing IL-37b) and Ad-eGFP (control adenovirus) ${ }^{[21]}$. Cultured MSCs were transduced with Ad-IL37b or Ad-eGFP at a multiplicity of infection of 200 in a-MEM media (without FCS) for $2 \mathrm{~h}$. Then, the virus-containing media was replaced with complete media, and the MSCs were cultured for 48 to $72 \mathrm{~h}$. Transfection efficiency was detected by flow cytometry. MSCs infected with Ad-IL37b or Ad-eGFP were named MSC-IL37b and MSC-eGFP, respectively.

\section{Real-time PCR (RT-PCR)}

Total tissue or cellular RNA from different samples was extracted with TRIzol reagent (Invitrogen, Carlsbad, CA, USA), and RT-PCR was performed with Fast SYBR Green Master Mix (Applied Biosystems, Beijing, China). The primer pairs are listed in Table 1.

Table 1. Sequences of oligonucleotides used as primers.

\begin{tabular}{lll}
\hline Target gene & & \multicolumn{1}{c}{ Sequence $\left(5^{\prime}-3^{\prime}\right)$} \\
\hline Mouse GAPDH & Sense & TGTGTCCGTCGTGGATCTGA \\
& Antisense & CCTGCTTCACCACCTTCTTGA \\
Human GAPDH & Sense & GAAGGTGAAGGTCGGAGTC \\
& Antisense & GAAGATGGTGATGGGATTTC \\
Human IL-37 & Sense & GGGAGTTTTGTCTCTACTGTGAC \\
& Antisense & CCCACCTGAGCCCTATAAAAG \\
Mouse IL-18R $\alpha$ & Sense & GAGTTTGGAGATGAGGCTAC \\
& Antisense & ACCTTCTCACACTTTGGTCC \\
\hline
\end{tabular}

\section{Western blot}

To detect the expression of IL-37b in MSC-IL-37b, cell lysates were boiled in sample-loading buffer, resolved in $4 \%-15 \%$ polyacrylamide gels and transferred to nitrocellulose membranes. The following antibodies were used: mouse anti- $\beta$ actin monoclonal antibody (1:2000 dilution; Sigma-Aldrich, St Louis, MO, USA) and rabbit anti-IL-37 polyclonal antibody (1:500 dilution). Primary antibodies were detected using horseradish peroxidase-conjugated secondary antibodies (Santa Cruz Biotechnology, Dallas, TX, USA). Immunoreactive bands were detected via a chemiluminescent reaction (ECL kit, Amersham Pharmacia, Piscataway, NJ, USA).

\section{Enzyme-linked immunosorbent assay (ELISA)}

To detect IL-37b activity, MSC-IL-37b supernatants were harvested 48 or $72 \mathrm{~h}$ after virus transfection. An ELISA was performed according to the manufacturer's instruction to measure IL-37b levels (R\&D Systems, Minneapolis, MN, USA).

\section{Induction of colitis and study design}

C57BL/6 mice (7-8 weeks old) were purchased from the Institute of Hematology, Chinese Academy of Medical Sciences (Tianjin, China). All the animals were housed in specific pathogen-free facilities and supplied with drinking water and food ad libitum. All the animal experiments were conducted 
according to the Principles of Laboratory Animal Care (NIH publication № 86-23, revised 1985) and the guidelines of the Animal Care and User Committee at the Institute of Hematology, Chinese Academy of Medical Sciences. For DSS-induced colitis, female C57BL/ 6 mice (18-20 g) were supplied with drinking water supplemented with 3\% (w/v) DSS for $8 \mathrm{~d}$. The induction of colitis was determined by weight loss, fecal blood, and colon length (upon autopsy) ${ }^{[22]}$. On d 0, mice were injected intraperitoneally with $0.5 \times 10^{6}$ MSCs diluted in $200 \mu \mathrm{L}$ of PBS or with PBS alone. All the mice were euthanized on d 10 after the start of the experiment.

\section{Histological inflammatory scores of the mouse colon}

At autopsy, the colon length was measured, and a $0.5-\mathrm{cm}$ section of the colon was fixed in $10 \%$ formaldehyde-saline. Histology scoring of H\&E-stained sections was performed in a blinded fashion according to a previously published scoring system $^{[23]}$ : cell infiltration: 0 , occasional inflammatory cells in the LP; 1 , increased infiltrate in the LP, predominantly at the base of the crypts; 2 , inflammatory infiltrate extending into the mucosa; 3 , transmural extension of the infiltrate; and tissue damage: 0 , no mucosal damage; 1 , partial (up to $50 \%$ ) loss of crypts in large areas; 2 , partial to total $(50 \%-100 \%)$ loss of crypts in large areas with an intact epithelium; 3 , total loss of crypts in large areas and of the epithelium. Finally, a combined score of inflammatory cell infiltration and tissue damage was calculated.

\section{Statistical analysis}

All the statistical tests were performed using GraphPad Prism software. Unpaired Student's $t$-tests were used to evaluate the differences in mean values between two groups. We used one-way ANOVA with Tukey's post hoc testing to compare more than two groups. Survival rates were analyzed using the log-rank (Mantel-Cox) test. Differences were considered to be significant when $P<0.05$. The data are presented as the mean \pm SEM.

\section{Results}

\section{Expression of IL-37 and IL-18 in UC mucosa}

Because the primers targeted a common IL-37 exon (exon 5) and the immunohistochemical staining with the polyclonal IL-37 antibody did not discriminate the isoforms, the general expression of IL-37 was evaluated in the inflamed mucosa of patients with active UC. As shown in Figure 1A, IL-37 mRNA expression was significantly elevated in the samples from the patients with active UC. IL-37 immunoreactivity was low in the normal mucosa (Figure 1B). In contrast, IL-37 immuno-

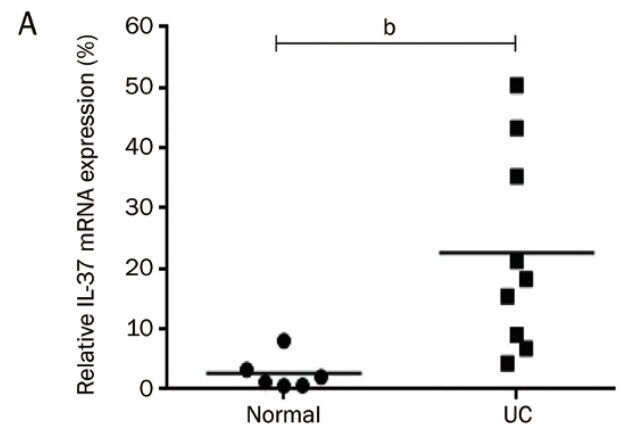

B

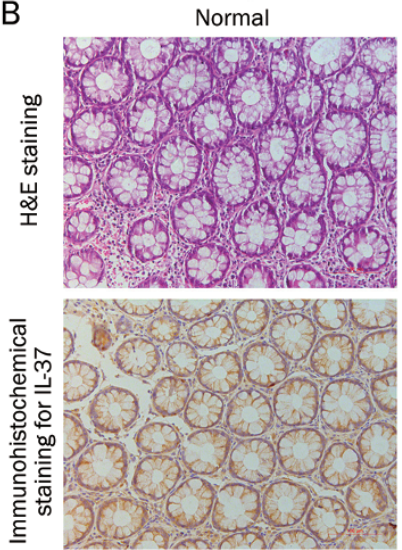

I

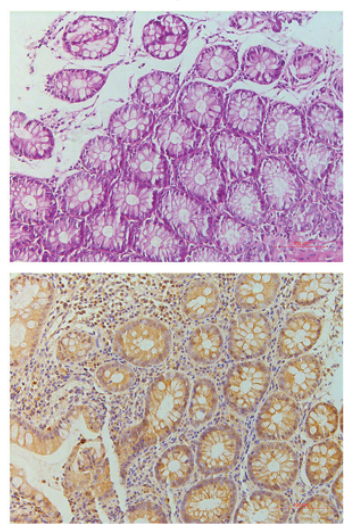

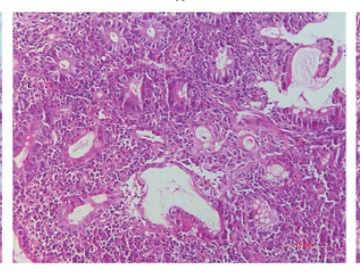

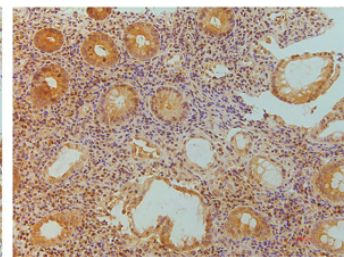

III

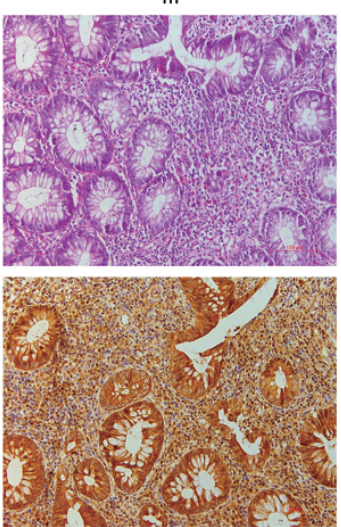

IV

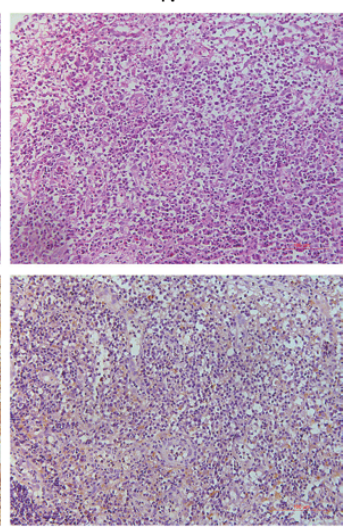

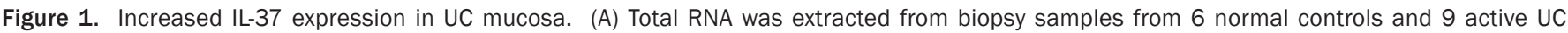

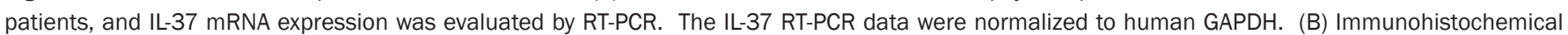

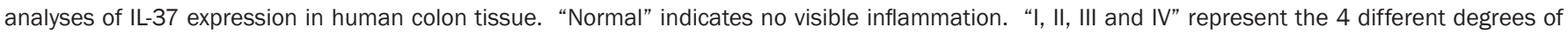

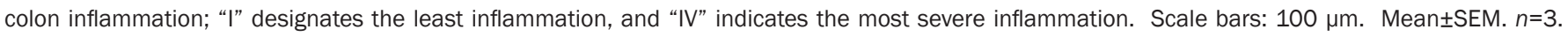
${ }^{b} P<0.05$. 
reactivity was dramatically increased in patients with active UC, mainly in the epithelial cells and infiltrating immune cells in the lamina propria. Furthermore, the protein expression of IL-37 increased in proportion to the severity of inflammation in the active UC tissues (Figure 1B). However, in affected tissues with florid acute grade IV inflammation, the epithelial cell damage, immune cell necrosis and formation of granulation tissues may have caused the decrease in IL-37 immunohistochemical staining.

As shown in Supplementary Figure 1, IL-18 immunoreactivity was not detected in normal mucosa. In contrast, IL-18 immunoreactivity was clearly detected in active UC patients, especially at the early stage of inflammation. Furthermore, the protein expression of IL-18 was negatively associated with that of IL-37. However, IL-18 staining increased in colon tissues with grade IV inflammation, which might be due to the presence of fibroblasts in the granulation tissue; fibroblasts are an important source of IL-18.

\section{IL-37b production by MSCs transduced with Ad-IL-37b}

At passage 3 or 5, cultured MSCs were positive for CD29, CD44 and Sca-1 but were negative for CD45 and CD31 (Supplementary Figure 2A). These cells were identified as MSCs by their capacity to differentiate into the osteogenic and adipogenic lineages (Supplementary Figure 2B). The transfer of AdIL-37b into MSCs was evaluated by fluorescence microscopy and flow cytometry; the transfection efficiency reached $85.9 \%$ (Supplementary Figure 3). IL-37b expression in MSC-IL-37b cells was confirmed by RT-PCR and Western blot (Figure 2A, 2B). MSC-IL-37b cells secreted detectable amounts of IL-37b $(12.00 \pm 1.02 \mathrm{ng} / \mathrm{mL}$ ) into the supernatant (Figure $2 \mathrm{C})$.

\section{IL-18R $\alpha$ mRNA levels in Tregs and MDSCs}

IL-18Ra is a major component of the IL-37 receptor complex. To investigate whether IL-37b exerts direct effects on Tregs and MDSCs, IL-18Ra expression in these cells was detected by RT-PCR. The relative IL-18Ra mRNA expression in Tregs $(1.89 \pm 0.30)$ and MDSCs $(1.13 \pm 0.21)$ was far lower than that in $\mathrm{CD}^{+}{ }^{+} \mathrm{CD} 25^{-} \mathrm{T}$ cells $(34.57 \pm 4.30)$, which are IL-18 effector cells (Supplementary Figure 4).

\section{Therapeutic efficacy in DSS-induced colitis}

Body weight change was determined as a therapeutic index. The body weight of mice that received only water remained stable during the 10-d period. On d 10, MSC-IL-37b-treated mice had lost approximately $10 \%$ less weight than PBS-treated mice $(83.74 \% \pm 2.01 \%$ vs $73.85 \% \pm 2.18 \%, P<0.01)$, but no significant differences were observed between PBS-treated mice and MSC- or MSC-eGFP-treated mice (Figure 3A). When we checked the mice every day, stool was not always visible near the anus of each mouse, especially at the advanced stage of colitis. Therefore, the disease activity index (DAI), which includes the stool state as an important grading criteria, could not be determined. Upon euthanizing the mice on $\mathrm{d} \mathrm{10}$, the colons were assessed for the presence of loose stool, bleeding, and macroscopic inflammation. Bleeding could be observed in the colon of PBS-treated mice, and loose stools were observed in the MSC-, MSC-eGFP-, and MSC-IL-37b-treated mice (Figure $3 \mathrm{~B})$. To assess colonic inflammation, the colon length of all the surviving mice was determined on $\mathrm{d} 10$. The average colon length of the MSC-IL-37b-treated mice $(5.73 \pm 0.17 \mathrm{~cm})$ was significantly longer than that of the PBS-treated $(4.38 \pm 0.23$ $\mathrm{cm}, P<0.01)$, MSC-treated $(5.12 \pm 0.11 \mathrm{~cm}, P<0.05)$ or MSCeGFP-treated $(4.98 \pm 0.13 \mathrm{~cm}, P<0.01)$ mice. Notably, the colon length of the MSC- and MSC-eGFP-treated mice was significantly longer than that of the PBS-treated mice (Figure 3C). MSC-IL-37b-treated mice $(2.90 \pm 0.24)$ had significantly lower histological scores than the PBS-treated (5.0 $\pm 0.4, P<0.01)$, MSCtreated $(3.90 \pm 0.33, P<0.05)$ or MSC-eGFP-treated $(4.20 \pm 0.37$, $P<0.05)$ mice. The histological scores of the MSC-treated mice were significantly lower than those of the PBS-treated mice $(P<0.05)$, but there was no significant difference between the MSC-eGFP and PBS groups (Figure 3D, 3E). During the 10-d period, no mice died in the MSC-IL-37b, MSC-eGFP, and MSC groups. However, 2 out of 6 mice $(33.3 \%)$ usually died in the PBS-treated group by the end of the experiment (data not shown).

\section{Proportion of Tregs in mouse splenic $\mathrm{CD} 4^{+} \mathrm{T}$ cells}

On $\mathrm{d} 10$, the mice were killed, and the percentage of Tregs among mouse splenic $\mathrm{CD}^{+} \mathrm{T}$ cells was determined by flow
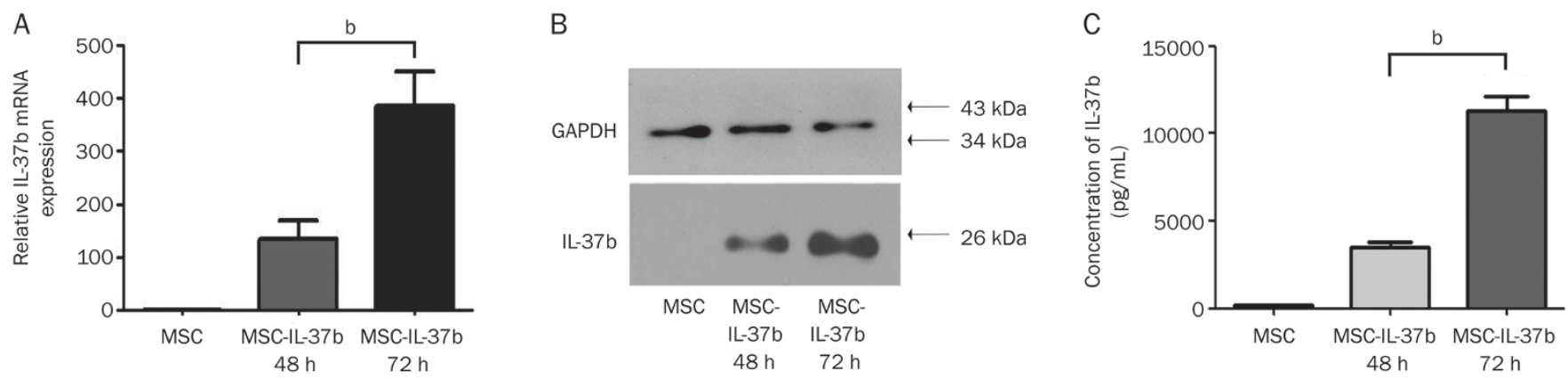

Figure 2. IL-37b expression was confirmed in Ad-IL-37b-transduced MSCs. (A) IL-37b mRNA expression was evaluated by RT-PCR 48 and $72 \mathrm{~h}$ after Ad-IL37b transfection of MSC. The IL-37b RT-PCR data were normalized to mouse GAPDH. (B) Western blotting analysis of IL-37b in MSC-IL-37b 48 and 72 $\mathrm{h}$ after Ad-IL-37b transfection. (C) IL-37b protein in the culture supernatant of MSC-IL37b was detected by ELISA. Mean \pm SEM. $n=3 .{ }^{b} P<0.05$. 
A

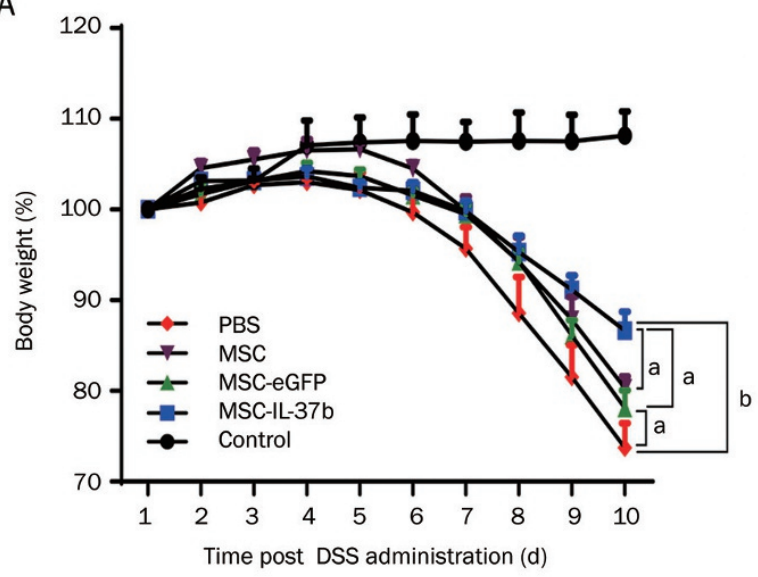

C

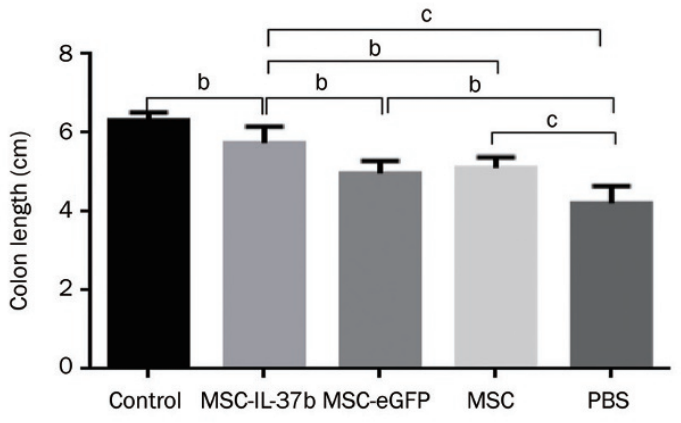

E

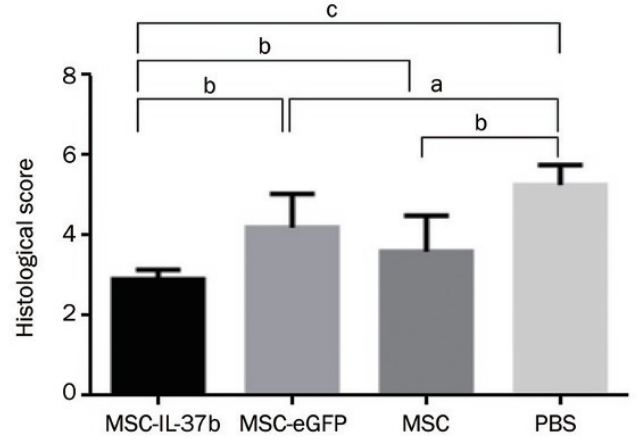

B

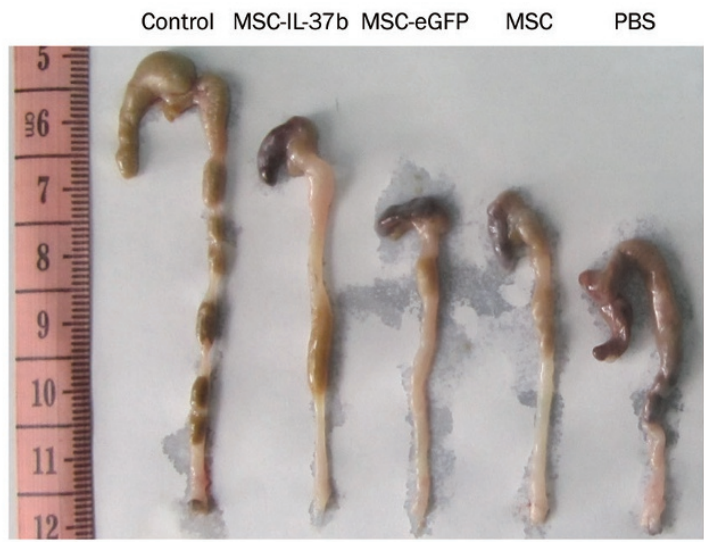

D
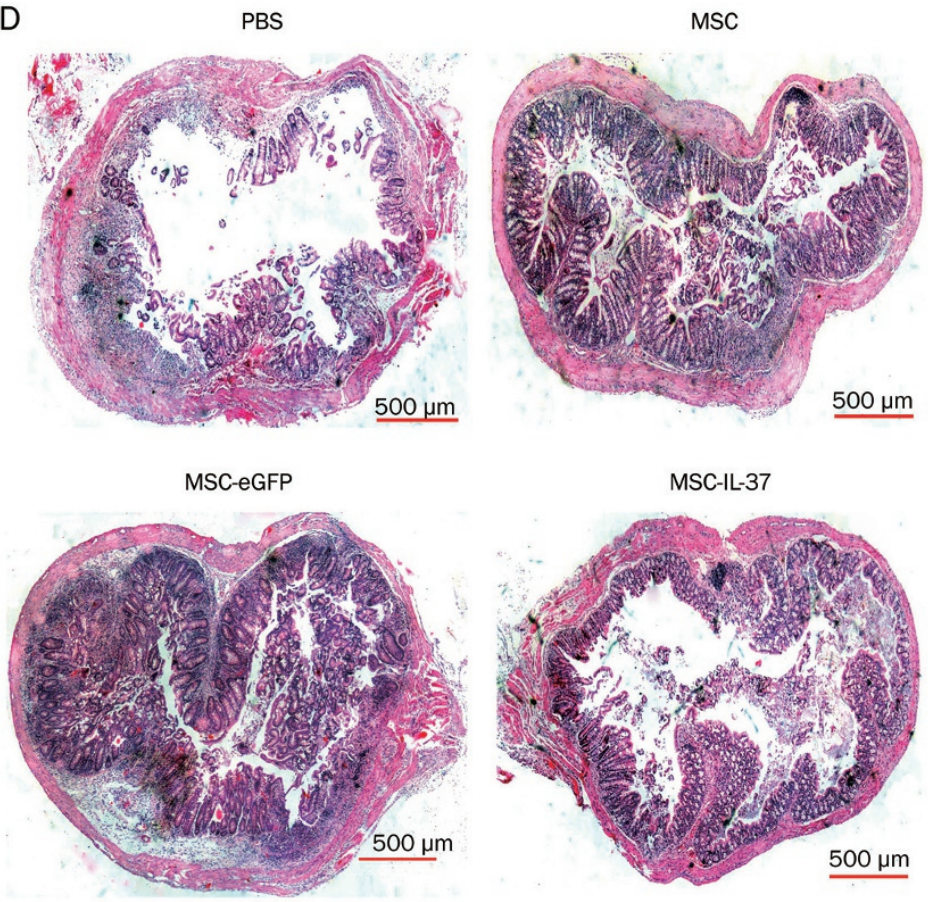

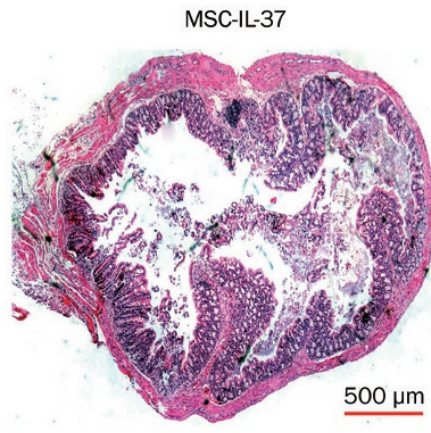

Figure 3. MSC-IL-37b prevented disease progression in DSS-induced colitis. Mice received 3\% DSS dissolved in drinking water for $8 \mathrm{~d}$. On d 0 , mice were injected with mouse MSCs, MSC-eGFP, MSC-IL37b or phosphate-buffered saline (PBS). Clinical evolution was monitored by body weight change and macroscopic and microscopic scores. All the mice were euthanized on d 10. (A) Body weight change during the course of the experiment. Body weight change is expressed as a percentage of the initial body weight on $\mathrm{d} 0$. (B) Macroscopic images of representative mouse colons harvested on d 10. (C) Assessment of colon length upon euthanasia on d 10 as an index of disease-related intestinal wall thickening. (D) Histological evidence that MSC-IL-37b prevents DSS-induced pathology. Photomicrographs of an H\&E-stained paraffin section of a representative mouse colon from each treatment group. (E) Histology scores were derived from microscopic analyses of colon cross sections from each mouse. Scale bar: $500 \mu \mathrm{m}$. The data are presented as the mean \pm SEM ( $n=6$ mice per group). ${ }^{\mathrm{a}} P>0.05,{ }^{\mathrm{b}} P<0.05,{ }^{\mathrm{c}} P<0.01$. The data are representative of three independent experiments.

cytometry. As shown in Figure 4, the percentage of Tregs in the MSC-IL-37b-treated mice $(18.95 \% \pm 0.99 \%)$ was significantly higher than that in the MSC-eGFP-treated $(12.53 \% \pm 0.70 \%$, $P<0.01)$, MSC-treated $(13.89 \% \pm 0.77 \%, P<0.01)$, or PBS-treated $(10.10 \% \pm 0.84 \%, P<0.01)$ mice. A significant difference was also observed between the MSC-treated mice and the PBS-treated mice $(P<0.05)$. However, no significant differences were noted between the PBS-treated and the MSC-eGFP-treated mice.

\section{Proportion of MDSCs in mouse total splenic mononuclear cells} The percentage of MDSCs among mouse total splenic mononuclear cells was analyzed by flow cytometry on d 10. As shown in Figure 5, the percentage of MDSCs was significantly higher in the MSC-IL-37b-treated mice $(4.85 \% \pm 0.57 \%)$ compared with the PBS-treated $(2.11 \% \pm 0.54 \%, P<0.01)$ or MSCeGFP-treated $(2.53 \% \pm 0.30 \%, P<0.05)$ mice but not the MSCtreated $(3.79 \% \pm 0.47 \%, P>0.05)$ mice. No significant differences 
A Gated on $\mathrm{CD}^{+} \mathrm{T}$ cells

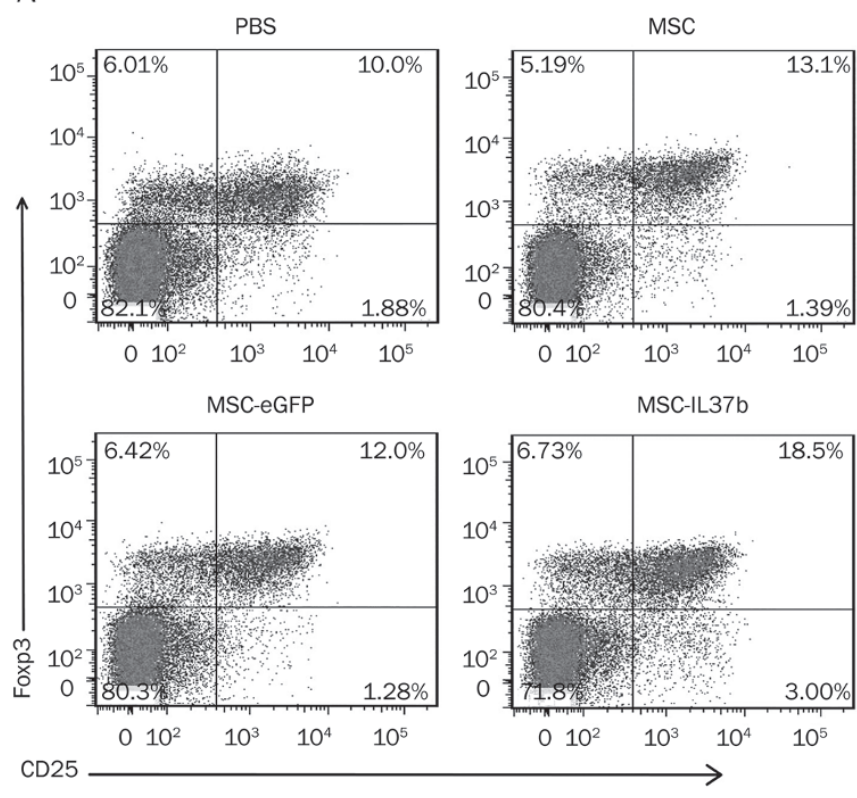

B

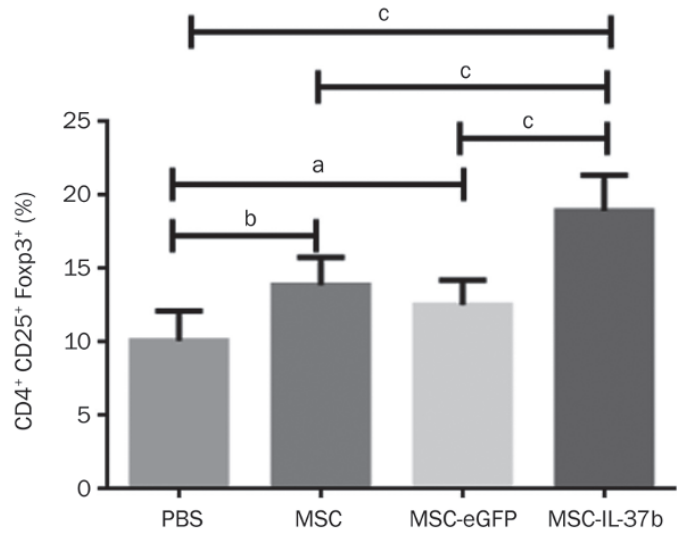

Figure 4. Treatment with MSCs, MSC-eGFP, or MSC-IL-37b induced splenic Tregs in mice with DSS-induced colitis. On d 10 after DSS administration, mice in each group were euthanized for analysis of splenic Tregs. Splenic cells were analyzed for CD4, CD8, and CD25 surface marker expression and Foxp3 intracellular expression by flow cytometry. (A) Dot plots of Tregs. (B) Summarized results of the percentages of Tregs. The data are presented as the mean \pm SEM ( $n=6$ mice per group). ${ }^{a} P>0.05,{ }^{b} P<0.05$, ${ }^{c} P<0.01$. The data are representative of three independent experiments.

were noted between the PBS-treated mice and the MSC- or MSC-eGFP-treated mice.

\section{Intracellular cytokine staining}

Based on the intracellular expression of IL-2, the percentage of $\mathrm{IL}^{-} 2^{+}$cells among splenic $\mathrm{CD} 4^{+} \mathrm{T}$ cells was significantly higher in the MSC-IL-37b-treated mice $(9.59 \% \pm 0.63 \%)$ compared with the MSC-eGFP-treated $(6.27 \% \pm 0.41 \%, P<0.01)$ and PBS-treated $(4.59 \% \pm 0.58 \%, P<0.001)$ mice but not with the MSC-treated mice $(7.25 \% \pm 0.68 \%)$. A significant difference was observed between the MSC-treated mice and the PBStreated mice $(P<0.05)$. However, no significant differences
A
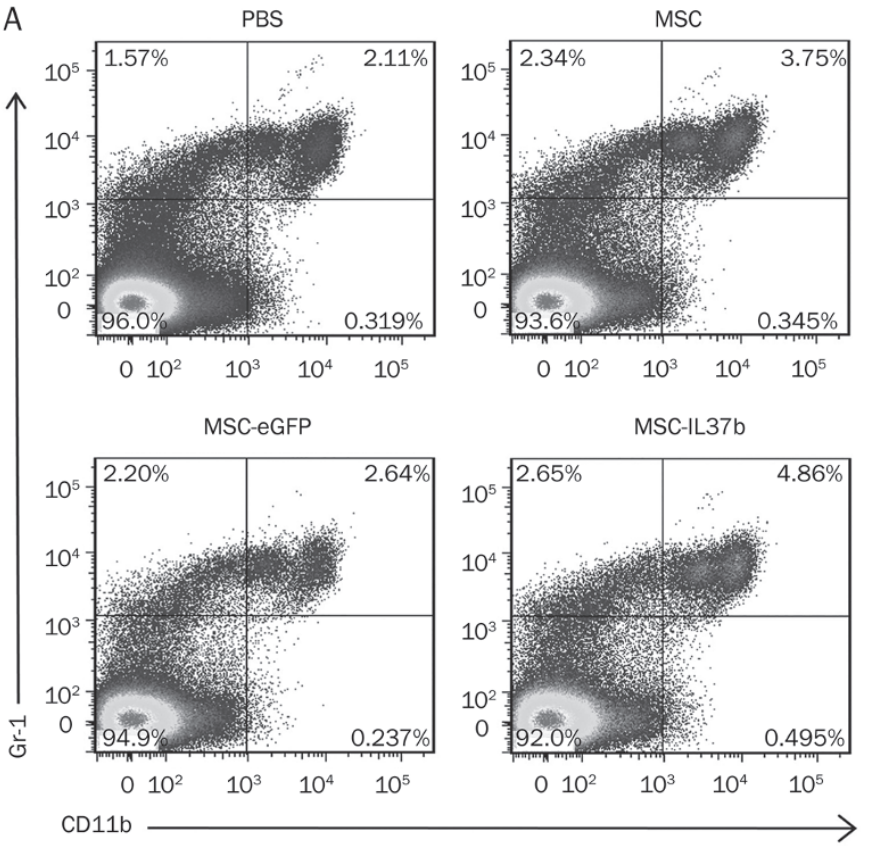

B

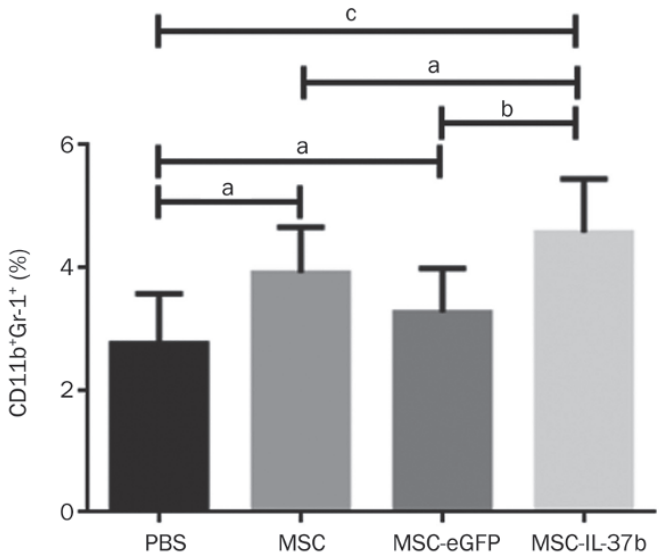

Figure 5. Treatment with MSC-IL-37b induced splenic MDSCs in mice with DSS-induced colitis. On d 10 after DSS administration, the mice in each group were euthanized to analyze splenic MDSCs. Splenic cells were stained for the CD11b and Gr-1 surface markers and analyzed by flow cytometry. (A) Dot plots of MDSCs. (B) Calculated results of the percentages of MDSCs. The data are presented as the mean \pm SEM $(n=6$ mice per group). ${ }^{\mathrm{a}} P>0.05,{ }^{\mathrm{b}} P<0.05,{ }^{\mathrm{c}} P<0.01$. The data are representative of three independent experiments.

were noted between the PBS- and MSC-eGFP-treated mice. IL-4 expression was not detected in splenic $\mathrm{CD}^{+} \mathrm{T}$ cells in each group (Figure 6A-6C). The percentage of IFN- $\gamma^{+}$cells among splenic $\mathrm{CD}^{+} \mathrm{T}$ cells was significant lower in MSC-IL$37 \mathrm{~b}$-treated mice $(3.33 \% \pm 0.66 \%)$ compared with MSC-eGFPtreated $(7.17 \% \pm 0.81 \%, P<0.05)$ or PBS-treated $(10.71 \% \pm 0.89 \%$, $P<0.001)$ mice but not with MSC-treated mice $(5.65 \% \pm 0.58 \%)$. The expression of IFN- $\gamma$ within splenic $\mathrm{CD}^{+} \mathrm{T}$ cells was also significantly reduced in MSC-treated and MSC-eGFP-treated mice compared with PBS-treated mice $(P<0.01$ and $P<0.05$, respectively). However, the expression of IL-17 within splenic 
A Gated on $\mathrm{CD}^{+} \mathrm{T}$ cells
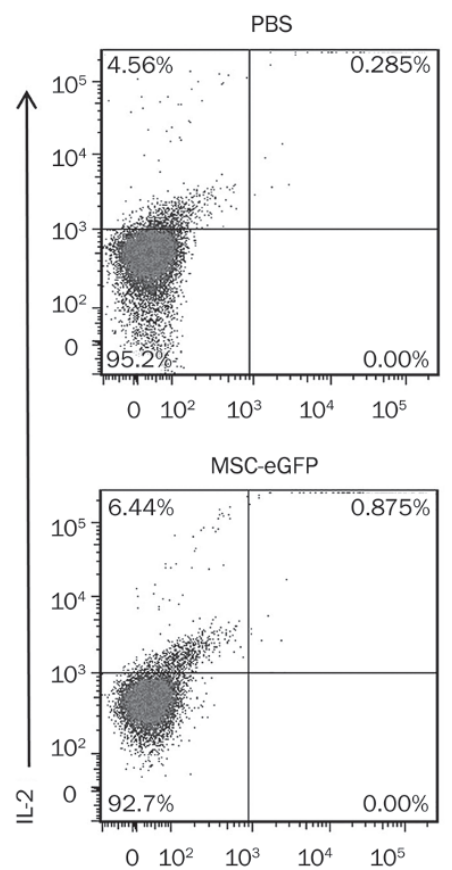

IL-4
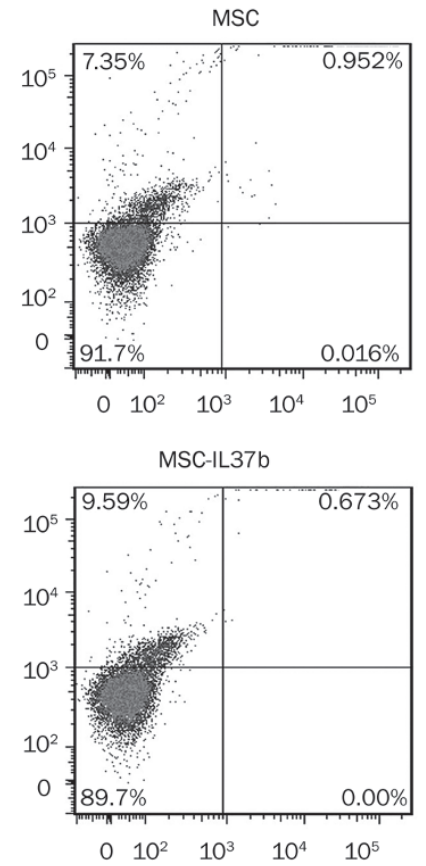

B
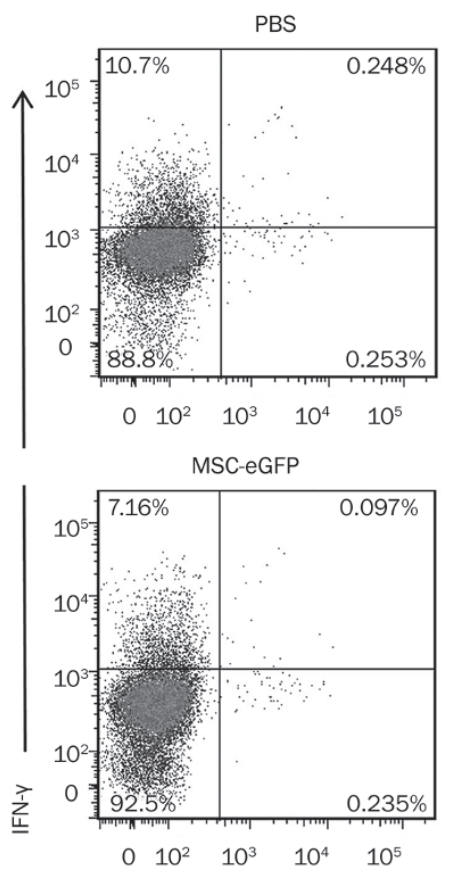

IL-17
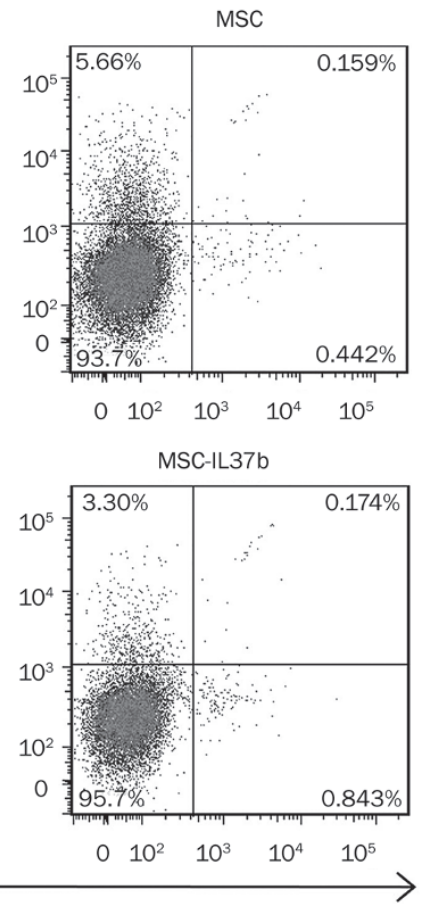

D

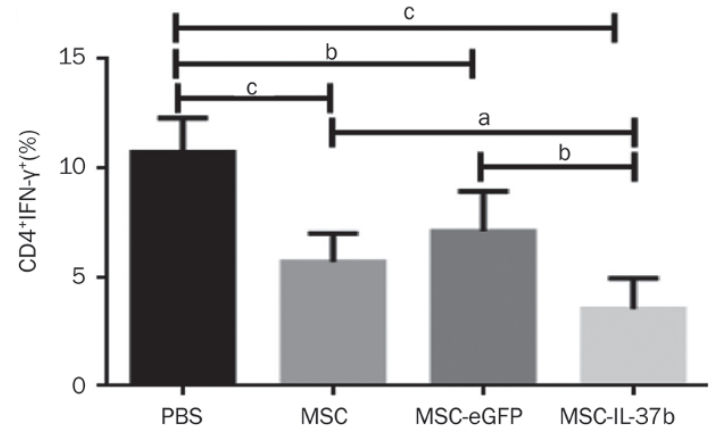

Figure 6. MSC-IL-37b induced IL-2 expression but repressed IFN-y expression in splenic CD4 ${ }^{+} \mathrm{T}$ cells in mice with DSS-induced colitis. On d 10 after DSS administration, mice in each group were euthanized to analyze intracellular cytokine production by splenic CD4 ${ }^{+} \mathrm{T}$ cells. Splenic cells were analyzed for the expression of the CD4 and CD8 surface markers and the IL-2, IL-4, IL-17, and IFN-y intracellular markers by flow cytometry. (A) Representative dot plots of IL-2 and IL-4. (B) Representative dot plots of IL-17 and IFN- $y$. (C) Frequency of IL-2 ${ }^{+}$cells among splenic CD4 ${ }^{+} \mathrm{T}$ cells. (D) Frequency of IFN- $y^{+}$cells among splenic $\mathrm{CD} 4{ }^{+} \mathrm{T}$ cells. The data are presented as the mean \pm SEM ( $n=6$ mice per group). ${ }^{\mathrm{a}} P>0.05,{ }^{b} P<0.05,{ }^{\mathrm{c}} P<0.01$. The data are representative of three independent experiments.

$\mathrm{CD}^{+} \mathrm{T}$ cells was not notably different among the animals in each group (Figure 6B-6D). The intracellular expression of IFN-Y in splenic CD8 ${ }^{+} \mathrm{T}$ cells was also repressed in MSC-IL37b-, MSC-, or MSC-eGFP-treated mice compared with PBStreated mice, which is similar to what was observed for splenic $\mathrm{CD}^{+} \mathrm{T}$ cells (data not shown).

\section{Discussion}

A recent clinical study reported that the protein levels of IL-37 were decreased in serum but increased in inflammatory colon tissue from IBD patients compared with healthy subjects, suggesting that IL-37 in the serum was consumed by the affected tissues to counteract mucosal inflammation in IBD $^{[19]}$. We showed that IL-37 expression was rarely detected in normal colon tissues but gradually increased with the severity of colon inflammation, further supporting the notion that IL-37 mediates a negative feedback mechanism to curb excessive inflammation. Moreover, we demonstrated that IL-18 expression negatively correlated with IL-37 expression in UC-affected colon tissues, suggesting that IL-37 might exert anti-inflammatory activity by suppressing IL-18 in addition to downregulating pro-inflammatory cytokines such as IL-1 $\beta$, IL-6, and TNF-a ${ }^{[10]}$.

MSCs infused either intravenously or intraperitoneally can 


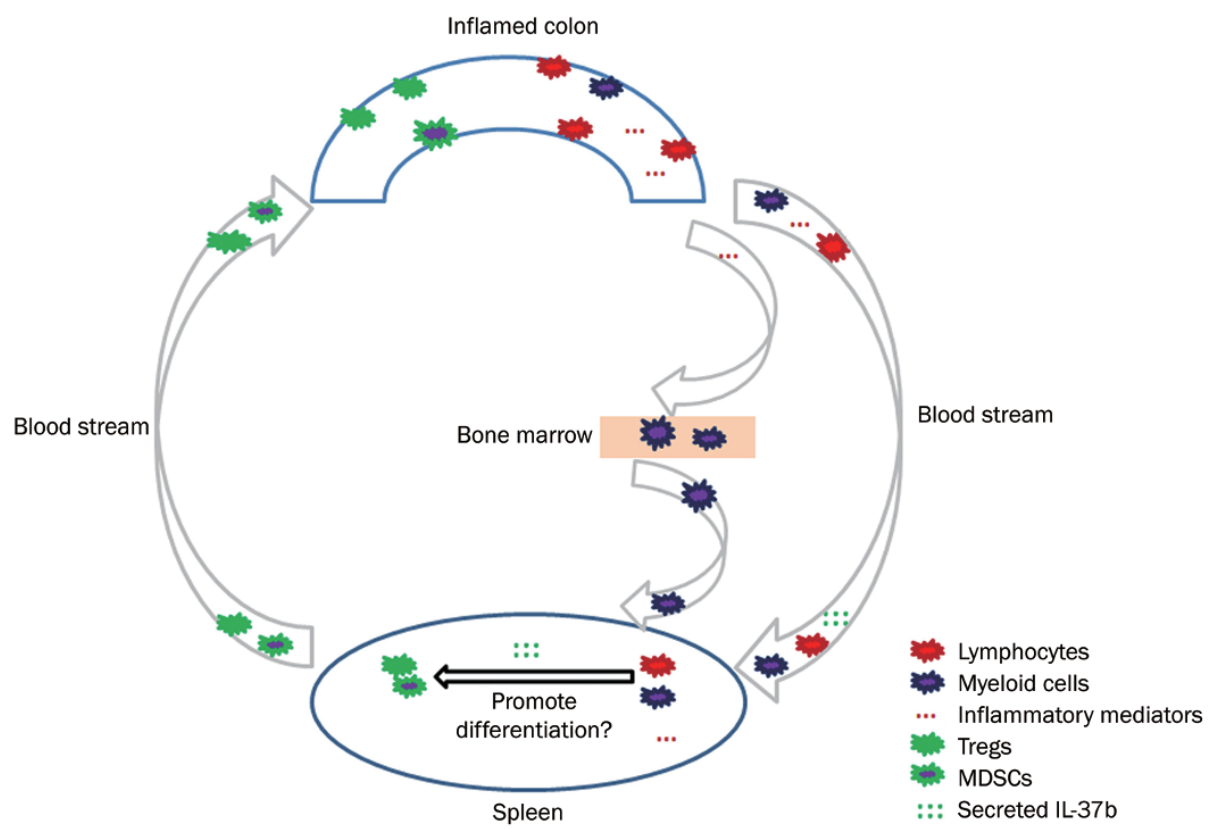

Figure 7. IL-37b is proposed to play a supportive role in the differentiation of Tregs/MDSCs in the spleens of mice with DSS-induced colitis. Lymphocytes and myeloid cells originating from the inflamed colon, bone marrow, or spleen are activated by inflammatory mediators during the development of DSS-induced colitis and then begin differentiating into functional cells, such as Tregs and MDSCs. The IL-37b cytokine produced by MSC-IL-37b circulates to the spleen via the blood stream and promotes the differentiation of Tregs and MDSCs. Finally, mature Tregs and MDSCs migrate to the affected colon and exert immunosuppressive activity to limit the harm caused by excessive inflammation.

improve experimental colitis ${ }^{[7]}$. In addition, they are ideal carriers for efficiently delivering exogenous genes because they migrate to the damaged organ with the genes, therefore achieving better therapeutic efficacy. For example, MSCs modified with the IL-10 or Kallikrein gene produced better improvements than MSCs alone in arthritis, lung ischemiareperfusion injury, and nephritis ${ }^{[24-26]}$.

In the present study, we utilized IL-37b gene modified mouse bone marrow MSCs (MSC-IL-37b) to treat DSS-induced experimental colitis and to determine whether IL-37b could enhance MSC therapy. After confirming the secretion of IL$37 b$ by MSC-IL-37b, we administered MSC-IL-37b via intraperitoneal injection because data suggest that more MSCs may be capable of migrating into damaged tissues ${ }^{[27]}$. However, using immunofluorescence, we failed to detect the MSCs transduced with Ad-eGFP or Ad-IL-37b (data not shown), perhaps due to the loss of MSCs (the cells possibly died) or the degradation of GFP protein during the long interval of $10 \mathrm{~d}$ between cell injection and tissue harvest.

Our study demonstrated that MSC-IL-37b has greater therapeutic efficacy in DSS-induced colitis compared with MSCeGFP and MSCs, suggesting that IL-37b gene modification can augment the therapeutic efficacy of MSCs. Although it has been reported that adenoviral modification of MSCs does not substantially affect the immunological properties of MSCs ${ }^{[28]}$, the efficacy of MSC-eGFP was diminished (although not significantly) compared with unmodified MSCs, indicating the cellular cytotoxicity of the transduced virus.
$\mathrm{CD} 4{ }^{+} \mathrm{CD} 25^{+} \mathrm{Foxp}^{+}{ }^{+}$Tregs play a pivotal role in limiting inflammatory diseases, including IBD, mainly by producing inhibitory cytokines and inhibiting dendritic cell (DC) maturation or function ${ }^{[29]}$. The percentage of Tregs among splenic $\mathrm{CD}^{+} \mathrm{T}$ cells from the MSC-IL-37b-treated mice was much higher than that from MSC-eGFP-, MSCs-, or PBS-treated mice, suggesting that IL-37b helps ameliorate DSS-induced colitis by upregulating Tregs. IL-37b might induce Tregs via DCs because IL-37b-expressing DCs exhibit enhanced induction of Tregs and display cytokine profiles that favor Treg generation $^{[12]}$. In addition, the finding that the frequency of Tregs was higher in MSC-treated mice compared with PBS-treated mice indicates that Tregs can be induced by MSCs, which is consistent with a previous report ${ }^{[5]}$.

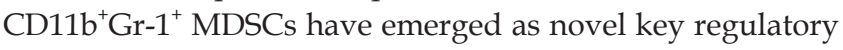
players in the contexts of tumor growth, inflammation, transplantation and autoimmunity by suppressing $\mathrm{T}$ cell responses. Moreover, the ability of MDSCs to promote the de novo development of Tregs in vivo has also been described ${ }^{[30]}$. It was reported that MDSCs were upregulated in the spleen of mice with colitis and that the adoptive transfer of MDSCs decreased intestinal inflammation and the levels of IFN- $\gamma$, IL-17, and TNF compared with controls ${ }^{[31]}$. Although the percentage of MDSCs among total splenic mononuclear cells was not significantly increased in the MSC-IL-37b-treated mice compared with the MSC-treated mice, this percentage was significantly increased compared with the MSC-eGFP- and PBS-treated mice, suggesting that the upregulation of MDSCs might be 
another way (but perhaps not the prominent way) for IL-37b to suppress inflammatory responses.

It has recently been reported that in addition to a nuclear function, IL-37b acts as an extracellular cytokine by binding to its receptor complex, IL-1R8-IL-18Ra, to activate a multifaceted intracellular anti-inflammatory program ${ }^{[32,33]}$. The mRNA expression of IL-18Ra was quite low in Tregs and MDSCs compared with $\mathrm{CD} 4^{+} \mathrm{CD} 25^{-} \mathrm{T}$ cells, suggesting that IL-37b may primarily indirectly, not directly, promote the differentiation of Tregs and MDSCs.

IL-2 is critical for the maintenance of Tregs in the periphery, and neutralization of IL-2 results in autoimmunity ${ }^{[4]}$. Therefore, in this study, the elevated expression of IL-2 in CD4 $4^{+} \mathrm{T}$ cells in the spleen might boost the differentiation of Tregs. The dominant IFN- $\gamma$ function in the immune system is to activate macrophages for enhanced effector function. IFN- $\gamma$ expression was suppressed in $\mathrm{CD} 4^{+}$or $\mathrm{CD} 8^{+} \mathrm{T}$ cells from the MSCIL37b-treated mice, suggesting that the inhibition of IFN- $\gamma$ production might be involved in the anti-inflammatory effect of IL-37b.

How could IL-37b affect the differentiation of Tregs and MDSCs or the expression of cytokines in the spleen of the colitis mouse model? Firstly, during the progression of DSSinduced colitis, naïve $\mathrm{CD} 4^{+} \mathrm{T}$ or myeloid cells in the inflamed colon could be activated by inflammatory mediators and migrate to the spleen, where the maturation of functional cells occurs. Secondly, the inflammatory mediators released from the inflamed colon could travel to the bone marrow and mobilize myeloid cells to the spleen, where MDSCs are induced. Thirdly, the inflammatory mediators could go directly to the spleen and promote the differentiation of Tregs and MDSCs or affect the expression of cytokines. After the injection of MSCIL-37b into the murine DSS-induced colitis model, the cells that survived could secrete IL-37b, which would circulate to the spleen and affect the differentiation of Tregs and MDSCs or cytokine production. Afterwards, functional Tregs, MDSCs and other immune cells would circulate through the blood stream to the inflamed colon to exert immunosuppressive activity; this process is called lymphocyte recirculation ${ }^{[34]}$. The above hypothesis of how IL-37b affects immune responses is summarized in a schematic (Figure 7). Notably, IL-37b protein was not detected in the serum of colitis model mice by ELISA upon euthanasia on d 10, possibly due to the consumption of IL-37b by CD4 $4^{+} \mathrm{T}$ cells or myeloid cells during Treg and MDSC differentiation. However, in addition to differentiation, abnormal emigration from bone marrow or lymph nodes could also affect the number of splenic Tregs and MDSCs during the development of colitis.

There are some limitations to this study. One, if another colitis model (for instance, TNBS-induced colitis) had been utilized in this study, the efficacy of IL-37b would have been further validated. Two, the frequencies of Tregs and MDSCs and the intracellular expression of inflammatory mediators in the inflamed colon and lymph nodes was not analyzed by flow cytometry due to the technical barriers of extracting mononuclear cells. Three, the DAI of the colitis model was not determined because of the difficulties in obtaining stool from some of the mice, especially at the advanced stages of colitis. Four, the effects of recombinant IL-37b on DSS-induced colitis were not explored.

In conclusion, we demonstrate that IL-37b gene transfer via an adenovirus expression vector improves the inhibitory effects of MSCs on experimental DSS-induced colitis not only by regulating cytokine production but also by inducing Tregs and MDSCs. Considering that MSCs alone showed antiinflammatory activity, albeit less potent activity than MSC-IL$37 \mathrm{~b}$, the anti-colitis effect in MSC-IL-37b-treated mice appears to have been caused by the cumulative action of MSCs and secreted IL-37b. Therefore, our study provides a novel approach to enhancing MSC therapy for IBD.

\section{Acknowledgements}

This work was supported by the National Basic Research Pro-gram of China (2013CB966904 and 2015CB964402), the National Natural Science Foundation of China (81200282, $81273217,81322007,81170007$, and 81370104), and the Recruitment Program of Global Youth Experts.

\section{Author Contribution}

Bang-mao WANG and Xiao-ming FENG designed the study; Wei-qiang WANG, Kui DONG, Lu ZHOU, Guo-hui JIAO, Cong-zhong ZHU, Wen-wen LI, Gang YU, Wan-tong WU, Song CHEN, and Zhi-na SUN conducted the experiment; Weiqiang WANG, Kui DONG, Yu-ming WANG, Wen-tian LIU, and Jie ZHANG analyzed the data; and Wei-qiang WANG, Lu ZHOU, Bang-mao WANG and Xiao-ming FENG wrote the paper.

\section{Supplementary information}

Supplementary Figures are available at the Acta Pharmacologica Sinica's website.

\section{References}

1 Fakhoury M, Negrulj R, Mooranian A, Al-Salami H. Inflammatory bowel disease: clinical aspects and treatments. J Inflamm Res 2014; 7: 113-20.

2 Lee TW, Fedorak RN. Tumor necrosis factor-alpha monoclonal antibodies in the treatment of inflammatory bowel disease: clinical practice pharmacology. Gastroenterol Clin North Am 2010; 39: 54357.

3 Glenn JD, Whartenby KA. Mesenchymal stem cells: Emerging mechanisms of immunomodulation and therapy. World J Stem Cells 2014; 6: 526-39.

4 Banchereau J, Pascual V, O'Garra A. From IL-2 to IL-37: the expanding spectrum of anti-inflammatory cytokines. Nat Immunol 2012; 13: 925-31.

5 Ko IK, Kim BG, Awadallah A, Mikulan J, Lin P, Letterio JJ, et al. Targeting improves MSC treatment of inflammatory bowel disease. Mol Ther 2010; 18: 1365-72.

6 Duijvestein M, Wildenberg ME, Welling MM, Hennink S, Molendijk I, van Zuylen VL, et al. Pretreatment with interferon-gamma enhances the therapeutic activity of mesenchymal stromal cells in animal models of colitis. Stem Cells 2011; 29: 1549-58. 
7 van Deen WK, Oikonomopoulos A, Hommes DW. Stem cell therapy in inflammatory bowel disease: which, when and how? Curr Opin Gastroenterol 2013; 29: 384-90.

8 Boraschi D, Lucchesi D, Hainzl S, Leitner M, Maier E, Mangelberger D, et al. IL-37: a new anti-inflammatory cytokine of the IL-1 family. Eur Cytokine Netw 2011; 22: 127-47.

9 Sharma S, Kulk N, Nold MF, Graf R, Kim SH, Reinhardt D, et al. The IL-1 family member $7 \mathrm{~b}$ translocates to the nucleus and down-regulates proinflammatory cytokines. J Immunol 2008; 180: 5477-82.

10 Nold MF, Nold-Petry CA, Zepp JA, Palmer BE, Bufler P, Dinarello CA. IL37 is a fundamental inhibitor of innate immunity. Nat Immunol 2010; 11: 1014-22.

11 McNamee EN, Masterson JC, Jedlicka P, McManus M, Grenz A, Collins $\mathrm{CB}$, et al. Interleukin 37 expression protects mice from colitis. Proc Natl Acad Sci U S A 2011; 108: 16711-6.

12 Luo Y, Cai X, Liu S, Wang S, Nold-Petry CA, Nold MF, et al. Suppression of antigen-specific adaptive immunity by IL-37 via induction of tolerogenic dendritic cells. Proc Natl Acad Sci U S A 2014; 111: 15178-83.

13 Sakai N, Van Sweringen HL, Belizaire RM, Quillin RC, Schuster R, Blanchard J, et al. Interleukin-37 reduces liver inflammatory injury via effects on hepatocytes and non-parenchymal cells. J Gastroenterol Hepatol 2012; 27: 1609-16.

14 Wu B, Meng K, Ji Q, Cheng M, Yu K, Zhao X, et al. Interleukin-37 ameliorates myocardial ischaemia/reperfusion injury in mice. Clin Exp Immunol 2014; 176: 438-51.

15 Bulau AM, Fink M, Maucksch C, Kappler R, Mayr D, Wagner K, et al. In vivo expression of interleukin-37 reduces local and systemic inflammation in concanavalin A-induced hepatitis. Sci World J 2011; 11: $2480-90$

16 Teng X, Hu Z, Wei X, Wang Z, Guan T, Liu N, et al. IL-37 ameliorates the inflammatory process in psoriasis by suppressing proinflammatory cytokine production. J Immunol 2014; 192: 1815-23.

17 Rachmilewitz D. Coated mesalazine (5-aminosalicylic acid) versus sulphasalazine in the treatment of active ulcerative colitis: a randomised trial. BMJ 1989; 298: 82-6.

18 Pullan RD, Rhodes J, Ganesh S, Mani V, Morris JS, Williams GT, et al. Transdermal nicotine for active ulcerative colitis. N Engl J Med 1994; 330: 811-5.

19 Li Y, Wang Y, Liu Y, Wang Y, Zuo X, Li Y, et al. The possible role of the novel cytokines IL-35 and IL-37 in inflammatory bowel disease. Mediators Inflamm 2014; 2014: 136329.

20 Zhu H, Guo ZK, Jiang XX, Li H, Wang XY, Yao HY, et al. A protocol for isolation and culture of mesenchymal stem cells from mouse compact bone. Nat Protoc 2010; 5: 550-60.

21 Wang WQ, Zhao D, Zhou YS, Hu XY, Sun ZN, Yu G, et al. Transfer of the IL-37b gene elicits anti-tumor responses in mice bearing 4T1 breast cancer. Acta Pharmacol Sin 2015; 36: 528-34.

22 Wirtz S, Neufert C, Weigmann B, Neurath MF. Chemically induced mouse models of intestinal inflammation. Nat Protoc 2007; 2: 541-6.
23 Smith P, Mangan NE, Walsh CM, Fallon RE, McKenzie AN, van Rooijen $\mathrm{N}$, et al. Infection with a helminth parasite prevents experimental colitis via a macrophage-mediated mechanism. J Immunol 2007; 178: 4557-66.

24 Manning E, Pham S, Li S, Vazquez-Padron RI, Mathew J, Ruiz P, et al. Interleukin-10 delivery via mesenchymal stem cells: a novel gene therapy approach to prevent lung ischemia-reperfusion injury. Hum Gene Ther 2010; 21: 713-27.

25 Li Y, Raman I, Du Y, Yan M, Min S, Yang J, et al. Kallikrein transduced mesenchymal stem cells protect against anti-GBM disease and lupus nephritis by ameliorating inflammation and oxidative stress. PLoS One 2013; 8: e67790.

26 Choi JJ, Yoo SA, Park SJ, Kang YJ, Kim WU, Oh IH, et al. Mesenchymal stem cells overexpressing interleukin-10 attenuate collagen-induced arthritis in mice. Clin Exp Immunol 2008; 153: 269-76.

27 Castelo-Branco MT, Soares ID, Lopes DV, Buongusto F, Martinusso $\mathrm{CA}$, do Rosario A Jr, et al. Intraperitoneal but not intravenous cryopreserved mesenchymal stromal cells home to the inflamed colon and ameliorate experimental colitis. PLoS One 2012; 7: e33360.

28 Treacy O, Ryan AE, Heinzl T, O’Flynn L, Cregg M, Wilk M, et al. Adenoviral transduction of mesenchymal stem cells: in vitro responses and in vivo immune responses after cell transplantation. PLoS One 2012; 7: e42662.

29 Vignali DA, Collison LW, Workman CJ. How regulatory T cells work. Nat Rev Immunol 2008; 8: 523-32.

30 Gabrilovich DI, Nagaraj S. Myeloid-derived suppressor cells as regulators of the immune system. Nat Rev Immunol 2009; 9: 16274.

31 Guan Q, Moreno S, Qing G, Weiss CR, Lu L, Bernstein CN, et al. The role and potential therapeutic application of myeloid-derived suppressor cells in TNBS-induced colitis. J Leukoc Biol 2013; 94 : 803-11.

32 Nold-Petry CA, Lo CY, Rudloff I, Elgass KD, Li S, Gantier MP, et al. IL37 requires the receptors IL-18Ralpha and IL-1R8 (SIGIRR) to carry out its multifaceted anti-inflammatory program upon innate signal transduction. Nat Immunol 2015; 16: 354-65.

33 Li S, Neff CP, Barber K, Hong J, Luo Y, Azam T, et al. Extracellular forms of IL-37 inhibit innate inflammation in vitro and in vivo but require the IL-1 family decoy receptor IL-1R8. Proc Natl Acad Sci U S A 2015; 112: 2497-502.

34 Gowans JL, Steer HW. The function and pathways of lymphocyte recirculation. Ciba Found Symp 1980; 71: 113-26.

(c) This work is licensed under the Creative SOMERIGHSHESEFVD Commons Attribution-NonCommercial-No Derivative Works 3.0 Unported License. To view a copy of this license, visit http://creativecommons.org/licenses/ by-nc-nd/3.0/ 